\title{
Grappling with Change: The South African Electricity Supply Industry
}

Paul S. Galen, Principal Policy Analyst, Program Analysis Office

\section{National Renewable Energy Laboratory Golden, Colorado}

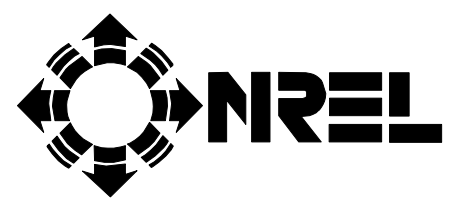

National Renewable Energy Laboratory 1617 Cole Boulevard Golden, Colorado 80401-3393 A national laboratory of the U.S. Department of Energy Operated by Midwest Research Institute for the U.S. Department of Energy Under Contract No. DE-AC36-83CH10093 


\title{
Grappling with Change: The South African Electricity Supply Industry
}

\author{
Paul S. Galen, \\ Principal Policy Analyst, \\ Program Analysis Office
}

National Renewable Energy Laboratory

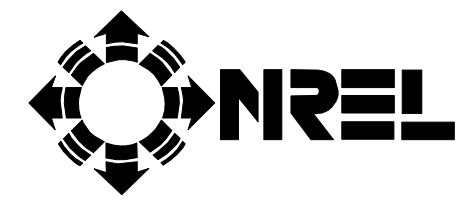

National Renewable Energy Laboratory 1617 Cole Boulevard Golden, Colorado 80401-3393

A national laboratory of the U.S. Department of Energy Managed by Midwest Research Institute for the U.S. Department of Energy under Contract No. DE-AC36-36CH10093

Prepared under Task No. PV807210

November 1998 


\section{NOTICE}

This report was prepared as an account of work sponsored by an agency of the United States government. Neither the United States government nor any agency thereof, nor any of their employees, makes any warranty, express or implied, or assumes any legal liability or responsibility for the accuracy, completeness, or usefulness of any information, apparatus, product, or process disclosed, or represents that its use would not infringe privately owned rights. Reference herein to any specific commercial product, process, or service by trade name, trademark, manufacturer, or otherwise does not necessarily constitute or imply its endorsement, recommendation, or favoring by the United States government or any agency thereof. The views and opinions of authors expressed herein do not necessarily state or reflect those of the United States government or any agency thereof.

Available to DOE and DOE contractors from:

Office of Scientific and Technical Information (OSTI)

P.O. Box 62

Oak Ridge, TN 37831

Prices available by calling (423) 576-8401

Available to the public from:

National Technical Information Service (NTIS)

U.S. Department of Commerce

5285 Port Royal Road

Springfield, VA 22161

(703) $487-4650$ 


\section{Acknowledgments}

I am indebted to many people without whose support, encouragement and advice this paper would not have been possible. Perhaps foremost are the members of NREL's FIRST Committee, Dave Ginley, Nancy Reece, Norman Hinman, and Doug Arent who believed in my proposed project and provided the majority of the funds needed to make it happen. The funding support provided by Allan Hoffman of DOE's Office of Utility Technologies, and Magate Sekonya the Chairman and Chief Executive Officer of the South African National Electricity Regulator (NER) was also necessary to making my project proposal a reality. I thank them both for having faith in me and in the importance of the work I and others on the NREL team did. I also want to acknowledge Jeffery Fang and Gary Nakarado for both their contributions to the work in South Africa and for their useful comments on the many early drafts of this paper. Ron White as always weighed in with useful comments. Finally, I wish to thank those many people in South Africa who provided me with information and insight into the new South Africa and to its electricity supply industry. While the list is a long one I would like to make special mention of Richard Goode at the Minerals \& Energy Policy Centre for again allowing me to join his staff, albeit temporarily, and gain useful perspectives on developments in the South African energy sector. Also, I wish to thank Gordon Sibiya, Wolsey Barnard, and Johann Basson of the Department of Minerals and Energy for their encouragement and support. I must also thank Grove Steyn from the NER and Jacques Messerschmidt of Eskom for their insightful review of this paper. Last, but definitely not least, I am indebted to Kevin Morgan who was Chief of Legal Services for the NER during my 8-month tenure in South Africa and at the NER. Kevin was an invaluable source of information and wisdom, challenging many of my ideas and forcing me to robustly support them or discard them. To Kevin and all those others who enriched my time in South Africa, I say thank you. 


\section{Contents}

Acknowledgments .




\section{Introduction}

This paper reviews the debate over the future structure of the South African electricity supply industry (ESI) with focus on the electricity distribution industry (EDI) segment. The importance of both new and old institutions in the ESI in facilitating change is discussed. The situation is viewed from the perspective of an "outside observer" who has spent a good part of the last 2 years following events in the South African ESI. The ESI situation reviewed here is very complex and connected to a myriad of other economic, financial, cultural, social, and political issues. I do not claim detailed knowledge of these related yet relevant areas. However, I believe that the views expressed here are sufficiently well grounded to offer them as a useful perspective and contribution to the debate. These are my views and do not necessarily represent those of the United States Department of Energy, its National Renewable Energy Laboratory, or any of the institutions that I have been associated with in South Africa. ${ }^{1}$

This paper opens with a brief review of the debate over the electricity distribution industry's future. Next, the problem prompting change in the EDI is presented, and two factors that may be causing the problem are briefly discussed. The various models proposed for restructuring the EDI are presented and briefly compared. The similarities between the various proposals are identified, as well as their differences. The lack of robust, quantitative analyses of the economic and financial impacts of the proposed models is discussed. The discussion concerning competition in the ESI is briefly summarized. A few observations concerning the nature of the EDI debate are given, along with some suggestions about why the debate has bogged down. The effect on the EDI debate by the larger discussion of restructuring the ESI to foster some level of competition is presented. The possible drivers motivating competition are identified and briefly compared to present conditions in South Africa. The role of institutions is then briefly discussed. Finally, some concluding thoughts are offered.

\footnotetext{
${ }^{1}$ Between December 1996 and March 1997, I was a visiting researcher at the Minerals and Energy Policy Centre and the Energy and Development Research Centre at the University of Cape Town. During that stay, the U.S. Department of Energy, the Development Bank of Southern Africa, and Eskom provided support for my work. Between October 1997 and mid-June 1998 I was on a visiting researcher assignment at the National Electricity Regulator (NER) and the Minerals and Energy Policy Centre (MEPC). Funds to support this assignment were provided by the National Renewable Energy Laboratory, the U.S. Department of Energy/Office of Utility Technologies, and the National Electricity Regulator of South Africa. Both visiting researcher assignments were sanctioned activities of the Sustainable Energy Committee of the US/RSA Bi-National Commission.
} 


\section{Summary of Observations}

The debate over the EDI's future structure has bogged down. There appear to be eight interrelated and mutually reinforcing reasons why this is so.

- Neither the stakeholders' economic and financial objectives, nor the economic and financial impacts of the proposed models, have been meaningfully quantified and compared. Consequently, the debate has been largely subjective because it lacks concrete quantitative estimates of parameters important to stakeholder interests.

- The debate has focused on the proposed models themselves, not on the specific objectives they are intended to achieve and the relationship of these models to individual stakeholder objectives.

- Although government has not recommended competition or privatization of the ESI at this time, concerns about both seem to underlie the discussion over the future structure of the EDI.

- Compared to other sectors of the economy, the ESI is performing relatively well. ${ }^{2}$ Although serious problems exist in the EDI segment of the industry ${ }^{3}$, they are not at a crisis stage that compels quick government action.

- Because of more pressing problems in other sectors and the limited time and attention government has to address all issues, the relatively well-performing ESI has not been the highest priority.

- Because it is a fundamental infrastructure industry, and even more a revenue source for municipalities, significant change in the ESI will have substantial effects on the entire economy, as well as significantly affecting local governance issues now being decided as part of the final transition to full democracy. The issues involved in ESI/EDI restructuring are complex. They have not been rigorously defined, robustly quantified, or thoroughly examined and input to an integrated analysis of the effects of change in the ESI concerning local governance issues. Consequently, lacking a consensus from key stakeholders on specific changes to the ESI and given the interrelationship between ESI and local government transformation, government has been unwilling to force change.

- Institutional issues affect the debate. There is considerable ambiguity over institutional roles and responsibilities in the ESI. Specifically, the authority and scope of jurisdiction of the National Electricity Regulator (NER) with respect to Eskom and the Eskom Council ${ }^{4}$ lacks clear definition and acceptance by all key industry stakeholders. This ambiguity has contributed to the lack of movement toward change. Additionally, the ambiguity has left NER and other ESI stakeholders in doubt as to what NER's role should be in facilitating or driving the ESI restructuring process.

\footnotetext{
2 The ESI is composed of three segments; the generation, transmission and electricity distribution industries. The generation and transmission segments are performing very well, not only in comparison to other infrastructure industries. The electricity distribution industry (EDI) does have serious problems, however, compared to other public sectors it is performing reasonably well and the problems it experiences are being dealt with, albeit often in an ad hoc fashion.

${ }^{3}$ These problems include an aging distribution infrastructure in need of refurbishment, quality of supply problems in some areas, and the generally weak financial position of most municipalities, which aggravates electric distribution problems.

${ }^{4}$ The Eskom Council was originally envisioned as the regulatory mechanism for Eskom. Over the years since the mid-80s it has come to act as a Board of Directors, not a regulator body. The Council is composed of various stakeholders in the industry as well as government representatives. Government appoints all members of the Council. The Eskom Council should not be confused with the Eskom Management Board, which oversees the actually running of the utility. In functional terms the Eskom Management Board acts as kind of a Chief Operating Officer (COO), whereas the Council acts like a Chief Executive Officer (CEO).
} 
- The upcoming 1999 national, provincial, and municipal elections may themselves be a reason not to make any significant changes in the relatively well performing ESI.

It is also important to note that the world has changed since the debate over the ESI's future began in 1993 within the larger context of significant political change in South Africa. There has been a global movement to competition and privatization of utilities. The benefits of doing so are now being tested in those countries that moved aggressively to implement these reforms. It is too early to make any definitive judgments. The results so far are mixed and unclear. More data is needed and will be available as time goes on. The lack, however, of consistent empirical evidence to unambiguously support the theoretical advantages of market competition among privately held utilities bears on a choice of two fundamentally different strategic approaches at the heart of the debate in South Africa. One is for the ESI to be centralized and directed by government. The other is to promote a marketdriven decentralized electric supply industry. As is discussed later, the drivers for competition are at best weak in South Africa today. Coupling this with the incomplete results to date of competitive reform in the electricity industries of many countries, and the natural inertia against institutional change, may be the main reason South Africa has not moved to implement the measures that have been debated over the last 5 years. 


\section{Background}

South Africa has been intensely examining its ESI for nearly 5 years ${ }^{5}$ to determine if and how it should be restructured to best support the country's new economic development and social upliftment goals. These goals are ambitious, essentially involving expansion of the developed economy to encompass the entire population of roughly 40 million. The demands on, and expectations for the ESI are many and varied. This diversity of interests and views is reflected in the debate. There is consensus on what is expected of the industry, namely, to provide adequate, reliable, and affordable electricity service to all citizens and segments of the economy. This means a large-scale electrification program to reach a significant portion of the nearly $50 \%$ of households currently without electricity service within the next 3 years. It also means tariff reform to promote equity and efficiency, and upgrading the reliability and service quality now being provided by some of the newly consolidated municipal authorities. ${ }^{6}$ However, no consensus exists on how best to achieve these results while accounting for time and resource constraints and balancing the interests of the various parties. There does, however, appear to be common acceptance of several important points.

- $\quad$ The EDI is fragmented, inefficient, and thus costly. It must be organized or rationalized in some way to ensure sustained financial viability, and to meet its responsibilities.

- Electrification is a critical infrastructure development activity that must be implemented.

- $\quad$ Electrification currently depends on cross subsidies, and will continue to do so for some time. The recurring cost of serving newly connected, low-usage customers is the most critical financial burden. It is estimated to be nearly R1.2 billion (in Rand [currency] @ 4.8R/U.S.\$ as of 1995) between 1996 and 2000.?

- $\quad$ Hidden cross subsidies should be eliminated or drastically reduced and tariffs should be cost based. ${ }^{8}$ Electrification should be supported through a transparent tax on suppliers or a levy on sales.

\footnotetext{
${ }^{5}$ One could assert that the debate actually began in 1989 when the former government and Eskom seriously looked at privatizing Eskom. Further, in 1991/92 the Energy \& Development Research Centre/University of Cape Town (EDRC/UCT) performed some initial studies looking at the ESI and electrification issues. In fact, the EDRC work became one base of information used by the National Electricity Forum (NELF) to identify, bound, and define the issues NELF would address. I have taken the NELF process to be the beginning of the debate (1993) because it represented the first attempt at review of electricity sector practices, performance, and policies by a truly representative range of the soon to be expanded electorate in South Africa.

${ }^{6}$ In 1996, the more than 1200 local authorities, mostly a creation of the old government, were consolidated into 760 through combining formerly white and black municipalities/townships. Currently in South Africa, local municipal authorities have the right/responsibility to provide electric service within their boundaries. Where they exist in rural areas local authorities also have these supply rights. In rural areas outside of municipal boundaries, Eskom (the national electric utility) has the right/responsibility for electric supply. Of the new local municipal authorities, only about half (394) actually supply electricity within their boundaries. The remainder is supplied either by other municipalities, or Eskom. In addition, Eskom provides service directly, usually at high voltage, to three large customers, and to 140 large customers through its Distribution Division. The municipalities supply about 80 large customers.

${ }^{7}$ Electrification subsidy estimates vary from 1.3 - 1.7 billion Rand per year in capital costs and just below 300 to 350 million Rand/year in operating (recurring) costs. The figures used in this article of 1.3 billion Rand/year in capital and 295 million Rand per year in operating (recurring) losses are taken from a Reconstruction and Development Program report (Ministry in the Office of the President, 1996).

${ }^{8}$ There is recognition that subsidies exist beyond those to support electrification. For example, some form of subsidized "lifeline" service will have to be maintained. It is agreed that the manner in which subsidies are collected and distributed, however, should be as transparent as possible.
} 
- The present approach to electrification of setting only numerical goals is wasteful, inefficient, and does not promote economic development effectively, or provide an equitable provision of basic service.

- Separating the three components of the industry-generation, transmission, and distribution - then introducing competition in supply at the wholesale level in the future may promote cost savings and economic efficiencies. How quickly competition is encouraged is a matter of debate, however.

Given the subsidies needed to accomplish electrification and the serious lack of service provision, and financial problems with many municipalities; a model is being sought that produces cost reductions to offset subsidies and improves the financial health and performance of the EDI. There are four competing models of the new EDI structure. They range from highly centralized to moderately decentralized. No model proposes competition in either wholesale or retail supply, although the concept of customer choice is embedded in the most decentralized model. As stated, however, this concept likely represents bypass of the newly formed distributors, not competition.

These models have been "on the table" almost from the beginning. The parties to the debate are familiar with the concepts behind them. There has been some quantitative analysis of these model's effects, but it has not been detailed, robust, or rigorous. Consequently, the debate over the models has occurred more on the grounds of basic beliefs rather than on the quantitative economic, financial, and technical impacts of each model on the industry and effect on the particular interests of the stakeholders. Perhaps because the debate has been qualitative, sufficient understanding and consensus has not been achieved to motivate government to make a final decision. In addition, although the problems in the EDI are serious, they are not at crisis levels - demanding government action to correct. With so many other pressing problems to address, it is understandable that government would not be motivated to take action to restructure a basic infrastructure industry that is working relatively well by comparison to others industries. This is especially true when implementing such a change could incur large "up-front" transaction costs in the first $1-2$ years before measurable benefits are realized. The danger in taking no action, however, is that it allows underlying problems to grow and entrench themselves further, possibly resulting in a crisis requiring more drastic and costly measures to correct than would have been needed had steps been taken earlier. 


\section{The Problem, the Proposals, and Wither Competition?}

\section{The Problem}

At present, roughly one-third of the nearly 400 municipal electricity distributors are experiencing serious financial problems. These financial difficulties produce two negative impacts. First, these municipal distributors cannot consistently provide adequate, reliable, and acceptable quality service. Second, some have problems in paying their bulk supply account to Eskom. The reasons for these problems are complex and likely vary with the particular municipality. Two forces exist, however, which may be driving them. These can be labeled as (i) microeconomic conditions (e.g., weak local economy or insufficient funds, and (ii) governance (e.g., mismatch of government structures to institutional structure/inefficiencies).

(i) Micro-economic conditions - simply stated this condition is: "there isn't enough money." The consolidation of white and black municipalities as part of the democratization process in the new South Africa merged the economic and tax bases of formerly separate local areas. Compared to the white municipalities, the black municipalities often had larger populations (generally poor), were under staffed, under funded, and had an inferior, deteriorating electricity infrastructure. Also, the former government's policies generally did not allow the level of commercial and industrial activity in black areas that would yield a tax base sufficient to support adequate municipal services. Lastly, exacerbating the situation, a practice of non-payment arose in black areas to protest against the former government's social policies. Prior to the consolidation in 1996, municipalities received an operating subsidy directly from government. This subsidy has not been increased to reflect inflation and increased real costs, and in some cases it has been decreased. Thus, when consolidated, many of the newly integrated municipalities could not cope financially or technically in many areas of service provision, including electricity distribution. Their revenue base is inadequate, the practice of non-payment is still something of a problem ${ }^{9}$, and their distribution systems need upgrading, which many cannot afford.

(ii) Governance-municipal government is in the interim stage of the transition from the former apartheid era structure to a final democratized structure due to be in place after the 1999 elections. The governance perspective holds that (generally) local economies are sufficient to support needed municipal service provision, or can be developed to handle them. The cause of the current financial difficulties is seen as "structural" problems with present governance forms that produce large inefficiencies. These inefficiencies result in the inability to collect required revenue and in the misallocation and waste of revenues collected. In October 1997, the national government released a "Green Paper on Local Governance" (Ministry for Provincial Affairs and Constitutional Development, 1997). ${ }^{10}$ Comments on the Green Paper were received in late November 1997 and a workshop was held in early December 1997 on a "Draft White Paper on Local Governance." A final "White Paper" has been submitted to the Cabinet. Presumably, parliament will act sometime in 1998 to adopt a new governance

\footnotetext{
${ }^{9}$ The non-payment problem is not limited to electricity charges. Property taxes and other municipal charges needed to generate revenues to provide needed public services are also subject to the non-payment problem.

${ }^{10}$ A "Green Paper" is a Discussion Document produced by government to serve as the basis for soliciting public comment on the matters addressed by the "Green Paper." After receiving public input, Government then revises the "Green Paper" into a "Draft White Paper," which once finalized and adopted by Cabinet will represent official government policy. The White Paper starts as a draft because all Cabinet Departments must review it before the full Cabinet can adopt it. Furthermore, the public gets another opportunity to comment on the Draft White Paper.
} 
structure for municipalities. Once this is done, the hope is that it will diminish and then eliminate the factors currently causing inefficiencies and management problems. This in turn will contribute to decreasing the overall problems of finance, revenue, and service provision.

Determining which of these two factors is causing the current problems, or the proportionate contribution of each, is important to answering the question of whether and how the EDI should be restructured. If governance is the major factor, and it can be sorted out satisfactorily, then perhaps restructuring the EDI need not address the current municipal financial and technical problems. ${ }^{11}$ Conversely, if the performance of local economies is the prime factor, then removing electricity distribution from the local authorities' direct control, and restructuring the EDI to allow for cost, revenue, and technical resource pooling (either with a centralized or decentralized model), may be the best means to ensure adequate and reliable service provisions nationwide. I have not examined the municipal governance issue sufficiently to comment on its relative effect on difficulties in the EDI. By adopting the Electricity Restructuring Interdepartmental Committee's (ERIC's) recommendations in the spring of 1997 (see next section), and incorporating them into the June 1998 "Draft Energy Policy White Paper," however, Government implicitly accepted the view that microeconomic conditions were the main driver behind the EDI's problems. Furthermore, adopting the ERIC recommendations also presumes that even if governance contributed to the problems, resolving these issues would not be sufficient to remedy the EDI's problems.

An important consideration is the municipalities' traditional dependence on revenue from electricity sales to fund other public services. Thus, they price electricity above cost to create the necessary surpluses. ${ }^{12}$ Removing electricity distribution would also remove this revenue source, which would have to be replaced. The proposed EDI models all account for this in one way or another, either by allowing local authorities to levy a tax on electricity sales or distribution, charging a franchise fee to a distributor providing service within municipal boundaries, or a combination of these. Currently, more than $41 \%$ of all municipal revenues are generated from electricity sales" (Ministry for Provincial Affairs and Constitutional Development, 1997, p. 76). Of course, municipalities would also shed the costs of directly providing electricity service under any of the current EDI restructuring models. Consequently, in theory at least, any levy or other revenue raising mechanism would not have to raise the same $41 \%^{13}$, but rather the amount of the current surplus, or the amount needed to support other services now paid for from electricity revenues, whichever is smaller.

Data on industry revenues collected by the NER for 1996 shows the EDI, as a whole, was financially solvent. ${ }^{14}$ Total revenues exceeded total costs by nearly R1.2 billion, net of the more than R1.3 billion in electrification costs incurred that year. The problem is the distribution of net revenues between municipalities. According to a study done for ERIC and included in its final report, in 1994, four municipalities earned $50 \%$ of the total surplus; 22 municipalities earned $75 \%$ of the total, and the top 100 earned $99 \%$. This left the remaining 300 or so municipalities, when combined, earning less than $1 \%$ of the total surplus that year. Figures for 1996 are presently unavailable, but there is no indication that this distribution has markedly changed. This strongly suggests that revenue transfers within the EDI are necessary. The question has been how best to effect such transfers. Consolidation of the EDI has been the answer, because it not only allows for the needed revenue transfers, but it also permits

\footnotetext{
${ }^{11}$ Of course, there are other reasons for wanting to restructure the EDI. Yet, these other reasons might be satisfied with less significant steps than any of the proposals to date.

${ }^{12}$ It should be noted that although electricity revenues fund other services, there is some sharing of facilities and administrative loads. Yet, in effect, municipalities are "taxing" through retail electricity tariffs to pay for other services.

${ }^{13}$ Recall that this $41 \%$ is the total revenue generated, of which a sizeable portion must pay for the costs of providing electric service. Under any of the EDI restructuring proposals the revenue needed to cover these costs would be generated from tariffs charged to customers by the new distributor(s).

14 This includes Eskom's separate distributors and the 394 municipal electricity distributors.
} 
other problems to be addressed. These other problems relate mainly to the fragmentation in the EDI and the proliferation of tariffs for service (mostly not cost-based) that cause economic inefficiency in the industry. Consolidation allows rationalization of the industry structure into a more efficient form, as well as redistributing revenues. The debate among stakeholders has been over what level and form of consolidation is most appropriate, not the concept of consolidation itself.

Of course, the fact that the EDI as a whole was solvent in 1996 does not mean it will remain so in the future. Real economic growth over the last few years has been between $2 \%-3 \%{ }^{15}$ If this trend continues, and if population growth outstrips economic growth ${ }^{16}$ then it is unlikely that the EDI will remain financially solvent if it continues to expand service to customers now without it, and maintain service levels to existing customers. Furthermore, government proposals to make Eskom subject to corporation tax, and pay dividends to government will drive costs and hence prices to retail suppliers up and exacerbate the solvency issue. The EDI consolidation, of course, cannot by itself solve this microeconomic problem. What it can do is try to create the greatest level of cost savings and economic efficiencies possible within the industry. This accomplishes two things. First, it reduces the cost burden of electricity provision on the national economy, thus contributing positively to overall economic health. Second, by reducing its own costs, it reduces the revenue it needs to operate, thereby placing the EDI in a better position to "ride out" low economic growth until higher growth is achieved. Consequently, the debate over the new consolidated EDI structure remains important, even if future industry solvency is not assured by whatever model is ultimately adopted. This, of course, assumes that it really is the microeconomic condition driving the EDI's current problems. If it is the local governance issue, then as suggested earlier, perhaps consolidation is not as essential.

The plethora of local governance issues, however, does bear on the ESI/EDI debate in other ways. Specifically, the effect that the adoption of any of the four proposed EDI models would have on the various political, governance, and administrative reforms currently being considered by Government in its White Paper process on local governance. Transformation of local governance is a more fundamental and enduring change than that being debated for the ESI. It deals directly with basic institution building, political empowerment, and the responsibilities and resources of all levels of government in providing public services and protecting the public interest. The White Paper on Local Governance acknowledges the ongoing debate over whether and how to transform the EDI. It does not discuss transformation in any detail. The White Paper notes the large share of local government revenues derived from electricity sales $(41.4 \%$ on the average), and states that "Alternate income from levies on electricity sales will be generated once restructuring within the electricity sector results in municipalities no longer playing a direct service provision role." ${ }^{\prime 7}$ It also confirms the government's current position as presented in its Draft White Paper on Energy Policy, that no part of the electricity sector be placed in private hands, but will remain as a public enterprise.

Given the interaction between the local governance and local electricity distribution, and the precedence that building new political institutions appears to take in the new South Africa, it seems

\footnotetext{
${ }^{15}$ However, real growth nearly evaporated in the first 3 quarters of 1998, and is projected to be almost flat in 1999.

${ }^{16}$ In fact, it is not even necessary that population growth lead economic growth, since the electrification program is adding new customers at the rate of about 450,000 per year many of whom will not use enough electricity to fully pay for their being connected. Further, even if economic growth flattens out and remains that way for several years, as long as new customers are being connected that are unable to pay for the full cost of connection or continuing service subsidies will remain necessary to provide for financial stability. These subsidies could come from within the EDI, that is, from industrial or commercial customers, or generation or transmission could subsidize distribution. In the former case one could claim EDI financial solvency since all cost were borne within the EDI, even if not by the customers causing the costs. The fact of the matter is that subsidies will continue to be needed regardless of what EDI restructuring model is adopted. The question is will they be cross subsidies internal to the EDI, to the whole ESI, or also come from the treasury.

${ }^{17}$ White Paper on Local Governance, Section G: Municipal Finance, subsection 1.1: Basic Features.
} 
that EDI restructuring will await the restructuring of local governance forms. It is unlikely that the national government will move forward quickly to restructure a vital component of municipal government separately from broader actions it takes to reformulate the political, governance, and administrative aspects of new municipal institutions, and thus their relationship and responsibilities in relation to provincial and national government. The quote listed in the above paragraph from the Local Government White Paper appears to confirm this sequencing.

\section{The Proposals}

A variety of proposals for restructuring the South African ESI have been examined since 1993, starting with the National Electricity Forum (NELF). NELF called for the creation of NER and a focus on the rationalization of the electricity distribution industry component of the ESI. NELF was followed by the Electricity Working Group (EWG) in 1995-96, whose most significant recommendation was to consolidate the EDI into the largest number of financially viable Regional Electricity Distributors (REDs) possible. Next came the Electricity Restructuring Interdepartmental Committee (ERIC) that essentially was a sub-cabinet level review of the EWG report and recommendations. Cabinet adopted the ERIC report's recommendations in March 1997 as the government "position" in final consultations with stakeholders before making a decision. In essence, the ERIC report endorsed the EWG recommendation of the REDs model, cost-based pricing with transparent subsidies ${ }^{18}$, retention of public ownership, municipal authority to tax electricity, and a levy of some type on the industry to fund electrification. The ERIC report's recommendations are essentially included in the government's Draft Energy Policy White Paper. The debate continues, however, and the models still "on-the-table" are:

1. Independent Regional Electricity Distributors (REDs): Consolidate all municipal electricity distributors and Eskom's distributors into the largest possible number of financially viable REDs. Government and the South Africa Municipal Government Association support this model, as did Eskom prior to its proposal of the Transition Holding Company.

2. Single Independent National Electricity Distributor (NED): Create one company by merging all municipal electricity distributors and Eskom's distributors. Under this model relatively autonomous regional operating divisions would be created. Proponents assert that doing this achieves the objective of REDs, but permits a stronger and financially healthier entity to be created. This model is supported by one of the Eskom unions, the National Union of Mineworkers (NUM).

3. Single Vertically Integrated National Electric Utility (VINEU): Consolidate all municipal distributors into Eskom, creating one national generation, transmission, and distribution electric utility. This is a traditional model. To adopt VINEU requires one of two assumptions: (i) that the electric industry is still a natural monopoly; or (ii) that even though competition in supply is possible, and might produce economic efficiencies, such benefits are offset by the difficulty of using a competitive industry to meet urgent social objectives, such as electrification, and extending service to the very poor. Another Eskom union, the National Union of Metalworkers of South Africa, supports this model (NUMSA).

4. Transition Holding Company: Create a holding company containing Eskom's generation and transmission divisions as one company, and make all municipal distributors and Eskom

\footnotetext{
18 "Transparent" is used in the sense that the tariff making process is not opaque and thus does not hide cross subsidies. With "transparency" customers should be able to learn what subsidies exist, their level, and who received them.
} 
distribution as another company held by the larger corporation. It is as if a NED and Eskom were "bought" and "held" by a larger corporation. Proponents of this model claim that it allows needed rationalization in the short-term, but preserves all options for the future. Furthermore, they claim that such a company would have a very strong balance sheet, which would be necessary if some level of cross subsidization had to be maintained. Eskom's management board supports this model, as does the Eskom Council.

How should these models be evaluated? This is not a simple question. Yet, logically any evaluation would start by identifying, quantifying, and comparing the net economic and financial benefits of each model, including the distribution and timing of said benefits. The EDI is, after all, a multi-billion Rand per year industry. Any proposals for change impacting on the level and distribution of such a significant sum of money requires that the effects be quantified and assessed. Yet, no such robust analyses have been done, or if done, they have not been offered in support of or in opposition to any of the current proposals. The ERIC report does contain some quantitative analyses, but it is primarily baseline information on the industry — a "snapshot" of its condition in 1994. This work was certainly useful to quantitatively define the industry and its problems in a first order manner. However, the report did not offer estimates on key parameters of an industry restructured into REDs or any other form. It provided no financial estimates; or tariff types and levels; or expected costs and their distribution; or revenue generation over time; or estimates of the impact on employment, public revenues, regional or national economic growth, the environment; or other pertinent economic and financial indicators. In short, the quantitative portion of the ERIC Report represented a good "scoping study" to identify areas meriting further detailed analysis. These analyses remain to be done.

The ERIC report recommended that the details of implementing the REDs model be assigned to a Professional Task Team (PTT), overseen by government with the aid of a Stakeholders Advisory Committee (SAC) ${ }^{19}$ Presumably ERIC, as well as the Draft Energy Policy White Paper, assumes that having made the strategic choice; the quantitative analyses, implementation steps, and schedule could be developed later. Without quantitative estimates of the costs and benefits of each model and the distribution of each to stakeholders, there has been no agreement on any model. The debate proceeds in a very qualitative and subjective way. In my opinion, this lack of quantitative estimates of each model's impacts is a major reason why no consensus has been reached. Of course, not all aspects of the restructuring, or perhaps even some very critical ones, can be quantified. Yet, surely each stakeholder has concerns over the economic and financial impacts of the proposals on their interests. These impacts are not meaningfully revealed for discussion and debate without quantitative estimates. Thus, it is not surprising that on matters with real and direct economic and financial impacts on all stakeholders, no agreement or decision has been reached without these impacts being estimated, debated, refined, and debated again until the scope of impacts on each party is defined and understood. It is certainly true that obtaining the quantitative analyses will not guarantee full agreement can be reached among all parties, yet without it no agreement has evolved. Thus, obtaining the quantitative analyses becomes a necessary, if not sufficient condition, for gaining consensus.

\section{Wither Competition?}

Overlaying the debate on EDI consolidation is the notion that competition is desirable in some form and at some time in the future. Neither the ERIC Report nor the Draft White Paper proposes adopting competition. Instead they recommend that competition be examined for its benefits at a later date. The

\footnotetext{
${ }^{19}$ Although the Draft White Paper adopts the idea of a Transition Team it does not specify its composition, or whether a stakeholders advisory committee would be formed to assist.
} 
idea of allowing competitive forces to operate in the ESI, however, has been discussed at some length over the last 5 years. In fact, the NER in its annual report (NER, 1997, p. 36) includes in its Vision Statement for the ESI, "Introducing competition into the industry, especially generation." Two forms of competition are most widely discussed. The first is wholesale competition where multiple generators compete to sell electricity to the REDs, the NED, or possibly the "transition company" for resale to retail customers. ${ }^{20}$ These generators could be Eskom's generation component (or the individual power stations within it), current municipal generators, Independent Power Producers (IPPs), and utilities or IPPs in neighboring countries having their power wheeled through the SAPP (Southern African Power Pool). Prices for wholesale electricity would not be regulated. The market would set the price. Transmission, both its price and its terms and conditions of service, would be regulated as an "open access" monopoly by the NER. Tariffs for distribution would also be regulated by the NER on a cost-of-service basis. Retail competition is also being considered, but not as seriously or concretely as wholesale competition. The form retail competition might take is not yet clearly defined. Presumably all customers would eventually have free choice of suppliers, with the REDs or the NED acting as an aggregator of loads for smaller customers, and providing "wires" services at regulated tariffs. ${ }^{21}$ It is unclear if the NED or the REDs would also own generation. Furthermore, the type of control and dispatch for the system has not been spelled out. Regional pools or possibly the SAPP itself could do this job.

Finally, one specific recommendation contained in the EWG and ERIC Reports and adopted in the Draft White Paper is that large customers have a choice of supplier. In the context of the current situation and recommendations, this means being able to take service directly from Eskom and bypassing the municipal authorities, or the NED, or the REDs if either of these is created. This recommendation is not a move to retail competition. Rather, it acknowledges that large customers should not have to continue to pay the above-cost tariffs presently charged by municipalities, and they should have access to adequate and reliable supply. Government's retention of this recommendation is curious in the context of the REDs or any other EDI model. All four proposed models, including the government's REDs model, intend to eliminate the current "municipal markup" by charging costbased rates, and assuring an adequate, reliable supply. Retaining the "customer choice" recommendation suggests that neither objective of the consolidation will be achieved, thus undermining the government's position on the best model. Furthermore, permitting large, high-load factor customers to bypass the new retail distributor may erode the very revenue base the distributor(s) require(s) to be financially solvent. Because the main point of consolidating the EDI and absorbing the transaction costs of doing so is financial solvency, allowing the best customers to bypass the REDs or NED may be counterproductive. Granted, conceptually the REDs (or NED) should be indifferent to whether they purchase power from Eskom to resell to large customers, or have the large customers take service directly from Eskom. The REDs, however, will be newly merged entities whose cost and financial characteristics may require a certain revenue flow and "distribution" charge to be viable. Thus, the bypass proposed through quasi-competition between Eskom and the new distributors might undermine the REDs, given the manner and climate within which they will be created. It is advisable that a brief, yet careful study be done to assess the chances for the "customer choice" principal to undermine the financial viability of the REDs, or a NED if that model is selected.

\footnotetext{
${ }^{20}$ It is difficult to imagine any form of competition with the VINEU in place. The "transition company" is very much like the VINEU in functionality, although one can envision ways to have it procure power competitively from its own generation division and from other suppliers. This, however, would likely be a cumbersome and inefficient arrangement. One that would be hard to police and one attempting to blunt the incentives for the "transition company" to always buy from itself. If one truly desired competition in wholesale supply, establishing what is essentially a vertically integrated monopoly and then trying to make it behave competitively is a long way around to achieving competitive results. Better to not establish it at all.

${ }^{21}$ The same issues associated with wholesale competition exist with retail competition and the "transition company." As with wholesale competition, it is hard to envision retail competition if a VINEU is adopted.
} 
Clearly, the REDs model adopted by government would not represent a barrier to permitting future competition in wholesale supply. Nor would it necessarily be a barrier to some level of retail competition. The NED model presents some problems for competition, springing from monopsony (single buyer, as opposed to a single seller monopoly situation) effects. These, however, might be overcome through regulatory means. The VINEU or the "transition" company models are not compatible with competition in any form. It might be possible, through heroic and costly efforts, to make the "transition company" operate in a competitive manner, but one has to ask: why set up such a model in the first place if competitive behavior and benefits are desired. Of course, as its name implies, the "transition company" is to be replaced by something else, which means that adopting it now is a decision to defer competition for a while. Adopting the VINEU model is an explicit rejection of competition as a viable form for the ESI. 


\section{Debate over EDI models. What is Really Being Argued?}

\section{Models Versus Objectives}

The debate over the ESI's future in general and the EDI in particular has been ongoing for more than 5 years. Government must ultimately decide whether and how to restructure the industry. It has, however, sought to obtain consensus from all affected parties on what should be done. The parties have publicly stated that the current status is unacceptable. They have also agreed that the EDI should be the first focus of change. But, they have not reached consensus on what to do and how to do it. Because government apparently wishes to endorse an approach, as opposed to deciding on one approach independently after receiving stakeholder input, a deadlock that maintains the existing structure has resulted. Can a consensus position be reached, and if so why has one not emerged so far?

The lack of quantified financial and economic impact estimates of each model on stakeholder interests is clearly one reason. Another one, perhaps related to the first, may be that the debate has focused on alternate models and not on the objectives achieved by applying a particular model. Stakeholders have their own objectives, of course. Thus, a threshold issue is what objectives are common among all stakeholders, which are different, and what differing objectives are incompatible. If there are apparent incompatible stakeholder objectives, then the question is whether and how they can be reconciled. Logically, this precedes discussion of models, since any given model should simply be a means to achieving a set of objectives. In addition, since most stakeholder objectives should be expressed in quantitative terms, deriving quantitative estimates of the model's impacts will advance the discussion of objectives, their degree of compatibility, and suggest how differing objectives might be reconciled.

Stakeholders agree that distribution is the major problem area in the ESI. Furthermore, they agree that the sustained financial and technical viability of the EDI is the key problem. Therefore, one shared objective of restructuring the EDI is to ensure its financial viability and thus its ability to deliver adequate, reliable, and reasonably priced service on a sustainable basis. Clearly, however, definitions of adequacy, reliability, and reasonable price may vary amongst the stakeholders. Furthermore, actions to achieve these objectives may impact on other interests held by each stakeholder, e.g., revenue from electricity sales for local government; number, type, and distribution of jobs for labor; input costs for industrial customers and effects on competitiveness; delivery of electrification for future residential customers; and so forth. It may be best for discussions around EDI restructuring to take a step back from specific models, and instead, identify objectives and address their commonality.

At best, focusing on objectives will yield an acceptable set of usefully stated objectives all stakeholders can agree upon. At worst, conflicting objectives can be identified and defined. Useful objectives are those that can be clearly stated and reasonably measured. ${ }^{22}$ If they are measurable, they can be quantified. Each model can then have its quantitative impact estimates compared to the set of stakeholder objectives.

\footnotetext{
${ }^{22}$ For example, "no job loss, other than by attrition in the first 5 years after a new model is implemented," is a usefully stated objective, whereas, "preserving employment in the industry" is not clearly enough defined to be easily applied and unambiguously measured. Another example of a usefully stated objective is, " $100 \%$ pass through to retail customers of any real price decreases at the wholesale level," whereas stating, "keeping retail prices low" is too vague and subject to debate over what is "low", and to "whom."
} 
After stating their objectives in the most quantitative terms possible, and before developing quantitative estimates of the various models' impacts, stakeholders might proceed by acknowledging the commonalties of the four models currently being debated. 


\section{Common Elements of All Currently Proposed Models}

There are at least 10 important elements common to each of the proposals.

- All consolidate the EDI.

- All acknowledge that adoption of the model will not involve retrenchments in the EDI.

- All remove direct provision of electricity service from municipalities.

- All call for a cost-based pricing policy.

- All allow some form of tax on the ESI to fund electrification.

- All permit municipalities to levy a tax of some sort on electricity service to replace revenues lost by removal of electricity sales.

- All require that any remaining and necessary subsidies in tariffs, e.g., "lifeline" tariffs to the poor, be transparent.

- While governance is not spelled out clearly, it is probable that stakeholders would be represented in a manner similar to how the current Eskom Council is constituted.

- No model proposes introducing competition into the EDI.

- All retain public ownership of the EDI.

These 10 commonalties all are fundamental parameters defining the new EDI, and hence its performance and impacts on stakeholders. There clearly, however, remain serious items to define and address, including:

- How costs will be defined for tariff setting purposes

- The actual composition of governing boards

- The mechanics and administration of municipal taxing to replace electricity revenues

- The salary and fringe benefit policies of a combined EDI workforce and effects on employment

- The legal requirements for the transfer of assets and liabilities to ensure current debt holders are satisfied

- The actual schedule for the consolidation

- The future intent regarding competition and privatization

- The manner in which viability will be defined

- How the actual restructuring process will be organized, managed, staffed, and overseen.

These matters, although difficult and complex, can likely be arranged given agreement on the basic principles of EDI structure and organization. Why then has not the debate moved to addressing these and other crucial points? First, as suggested previously, little understanding of the quantitative effect of a given model on stakeholder objectives is available for discussion and negotiation. Yet, as important to resolving the EDI issues as are quantitative impact estimates, 
there seems to be a more fundamental issue involved, namely, the role of competition and privatization in the ESI. Government, through the recommendations contained in its Draft Energy Policy White Paper, is not proposing either competition or privatization at this time. It seems, however, that stakeholder desires for (or fears of) these two actions is motivating the debate to some extent. 


\section{The Prospect of Competition and Privatization}

Government is seriously considering further commercializing Eskom by making it subject to corporation tax and dividend payments to the government as the sole shareholder. This policy could extend to any of the proposed models, in which instance the shareholders would be the municipalities and government. Neither action towards commercialization would mean that privatization or competition must follow, although requiring Eskom and the successor organization(s) in the EDI to pay tax and dividends is a necessary step before privatization. But, it bears emphasizing that privatization does not mean competition, nor does competition mean privatization. The ownership status of utilities is not the sole determinant of whether competition is possible or desirable. A government policy declaration does not create competition. The market must be inherently competitive for competition to be possible. Government policy can prevent competition from occurring or allow it to happen, but cannot create it. In fact, declaring a market competitive when it is not leads to either an unregulated monopoly or an oligopoly, which in turn will extract "monopoly rents" at the expense of economic efficiency. In simple terms, customers will pay more for the product than they would otherwise. Monopolies are typically regulated primarily to prevent the monopolist from charging inefficient prices, not to ensure equity. ${ }^{23}$

\section{Competition and Privatization}

It seems clear that, with the exception of government organizations like the NER and the Department of Trade \& Industry (DTI), generally stakeholders are at best unsure about competition, and leery of privatization. Government's official Cabinet statements on the matter, and the Draft White Paper, are clear. Neither competition nor privatization is recommended at present. One would think that stakeholder concerns about competition and privatization would not influence their approach to the debate over EDI models. Yet, the government institution with the most direct responsibility for the ESI (the NER) states in its 1997 vision for the industry that it wishes to promote both competition, and participation of the private sector in the ESI. DTI recently released a report embracing market economics as a cornerstone for economic growth and development. International investors and development agencies continue to express a preference for competition in infrastructure industries like electricity supply. Stakeholders are aware of all these statements and preferences. Therefore, despite the Cabinet statement, the debate over centralized and decentralized EDI models is partially a debate over the advisability and feasibility of future competition in the industry. Clearly, if a centralized EDI model is adopted, especially if it is one creating a single national vertically integrated utility, moving to competitive electricity supply within the next decade or so will be extremely difficult. Thus, to the extent given stakeholders believe competition in the ESI is not in their or the nation's interest, and wish to prevent competition, supporting a centralized model helps achieve that objective. In fact, the more centralized the better.

\footnotetext{
${ }^{23}$ This view of the primary reason and justification for economic regulation is not universally shared. Some would argue that maintaining equity (as in fairness) in the provision and pricing of services is at least co-equal in importance to insuring economic efficiency through proper pricing. While there is merit in this argument, I believe that since regulation was seen as the second best solution, with competition being the first best, then it follows that if competition is not possible due to the desire to gain the economies possible by allowing only one service provider, regulation is substituting for competition. Competitive markets do not allocate benefits and costs to market participants based on fairness, but rather on efficiency. Price determines efficiency, although some would say that price reflects the level of efficiency in a market. Either way regulation is intended to mimic market pricing to the extent possible. It is certainly true that other public policy goals such as equity have been given to regulation and regulators over the years. The point here, however, is that the original conceptual basis and justification for regulation was efficiency, not equity.
} 
Those stakeholders supporting the less centralized REDs model, such as local government, do not necessarily do so because they want to pave the way for competition. Rather, they appear to support a model they believe will accomplish four objectives.

- It will rationalize the industry and hopefully minimize the cost of service.

- It will provide an electricity service in a way that is closer and more responsive to local concerns than they believe is likely with a more centralized model.

- It will allow municipalities to avoid the cost of providing that service by removing direct provision of the electricity service from local government. As long as they are permitted to replace the revenue lost through a tax, they may be better off financially.

- It will minimize or eliminate regional cross subsidies.

The electricity industry worldwide has been moving away from a vertically integrated, stable, monopoly structure to a horizontally organized, more volatile, and competitive one. Why? Mainly for two related reasons. First, where the cost of new electricity generation is often significantly below the average embedded cost of existing utility-owned generation new suppliers seek to enter electricity markets to compete with incumbent utilities. Second, as the need for new capital investment arises, governments are less willing than before to bear all the investment risk of acquiring new resources and private capital does not wish to lend to entities with limited and/or uncertain cashflow. Through privatization, however, investment risk can be shifted to the private sector along with the rewards possible for taking the risk.

Recall that the economic regulation of utilities was perceived as the second best solution to providing least-cost service in an industry believed to be inherently monopolistic. Thus, regulation was intended to substitute for competition since competition was not possible. However, when the supply (generation) market began exhibiting competitive characteristics, the need for continued regulation diminished, but did not disappear. In order for new suppliers to get their product to market, they need access to transmission and distribution (T\&D) systems, which generally are owned by the incumbent utilities. The T\&D market, unlike electricity generation, retains strong monopoly characteristics. Thus, to ensure that current owners of T\&D systems do not seek to extend their monopoly in this area to the commodity (electricity) by restricting access, and/or through discriminatory pricing of T\&D services or through a combination of both, three things are required.

- T\&D services must be unbundled from each other and generation, and separately priced.

- Economic regulation of these two monopoly services must be retained and applied.

- T\&D system owners or operators must fully divest themselves of generation assets.

Unless all three of these actions are taken it remains possible for anti-competitive behavior to occur, thus lowering economic efficiency and imposing unnecessary costs on the economy. All three of these steps are being implemented or considered in those countries that have moved to competitive electric markets. ${ }^{24}$

The drivers behind competition in electricity markets have been the desire to reduce costs, reduce prices to end-users, improve service quality, and/or enhance availability of supply, thereby benefiting the entire economy. New suppliers wish to enter the market because they believe they can provide

\footnotetext{
${ }^{24}$ The divestiture of generation by utilities owning generation is still being debated in many instances. The reason is that early experience showed that retention of ownership of transmission assets by utilities also seeking to compete in the generation market provided them with both the incentive and means to distort the generation market to their advantage even with open access rules in place.
} 
electricity at a cost well below that of incumbent suppliers. Allowing them entry through competition is a means to access the lower prices, enhanced service quality for the economy or both. Do the same drivers exist in South Africa? Eskom's costs and the prices it charges to recover them are among the lowest in the world. Eskom provides adequate and reliable electricity supply. Clearly, Eskom can produce further efficiencies to drive costs and prices down in real terms. In fact, Eskom has a price compact with the government to do just that, and has been accomplishing it. ${ }^{25}$ Prices charged by municipal suppliers to their customers are $47 \%$ higher on average $(17,2$ cents per kilowatt-hour [c/kWh] versus $11,7 \mathrm{c} / \mathrm{kWh}$ ) than Eskom's distribution price. This difference mainly, but not entirely, represents the cost of distribution and the municipalities' pricing policy of creating a surplus from electricity sales to fund other municipal services. ${ }^{26}$ Clearly, municipal customers would prefer to pay less for service. Yet, if the prices charged them reflect the cost of needed municipal services, even if the surpluses were removed from tariffs and replaced by a tax, these customers would face essentially the same effective price. Service quality is an issue for some municipalities, but generally these are the smaller ones. The issues involved can be addressed by means other than fostering competition, as the current set of EDI proposals attest.

By developed country standards, electricity prices are low in South Africa; even with the higher prices charged by municipalities. Service quality and adequacy is generally acceptable. Thus, two of the three main drivers that motivate competition, namely cost/price and service quality, are weak in South Africa. The third, however, adequacy of supply, remains. The country is now in an excess capacity situation, and will remain so well into the next century at present growth rates. However, if South Africa meets its economic growth goals between 24,000 megawatt electric $\left(\mathrm{MW}_{\mathrm{e}}\right)$ and $54,000 \mathrm{MW}_{\mathrm{e}}$ of new capacity must be brought in during the next 20 years. Admittedly, given the flattening out of real economic growth recently it seems unlikely that those ambitious $6 \%$ annual growth goals will be met. Yet, unless one assumes a prolonged deflationary economy, eventually new investment will be needed. It is the timing of when that remains uncertain. An investment of between R288 billion to R648 billion (in 1997 terms [U.S.\$60 billion and U.S.\$135 billion]) is needed to meet the demands associated with such large economic growth. ${ }^{27}$ Given the amount required, the risks associated with investments of this magnitude, the other demands on the fiscus,

\footnotetext{
${ }^{25}$ While Eskom has been reducing costs and prices in real terms there is a question as to whether it can continue to do so at its present pace. It can be argued that Eskom's record of lowering costs and prices derives from several factors that are not related strongly or at all to efficiency. First, that Eskom started from an abnormally high level due to over building in the 1970s and 1980s. Second, that capital costs were subsidized in the 1980s. Third, Eskom's coal costs are very low and unlikely to remain so in the future. Fourth, the cumulative effect of not having to pay taxes or dividends. Fifth, its low cost of debt because all risk has been passed on to customers. Sixth, it is completing its construction program, and seventh it has retired a large portion of its debt. All these factors have combined to reduce costs, but most will not likely be available in the future.

26 The price Eskom charges municipalities for bulk power is higher than what it charges its own retail distributors. The municipalities, of course, complain about this. Part of the added cost represents Eskom's electrification costs. Municipals note that they have electrification targets as well, and they are essentially being charged twice. The amount Eskom charges municipalities above what it charges itself, however, is not entirely explained by the electrification amount. It appears that the transmission prices to municipalities are higher as well. There may be a cost basis for this, or it may have to do with the "zone" transmission pricing policy approved by the NER. It likely involves both things. It is beyond the scope of this paper to address this subject in depth or detail. It is recognized, however, that these matters have been and continue to be important matters for debate.

27 The figures given for necessary capacity additions and associated capital investment are illustrative only. Further, the correlation between percent economic growth and annual percentage growth in electricity demand is not one-to-one. Thus, if the current target of $6 \%$ real economic growth were met, one would expect electricity demand growth to be lower on average over a 20 -year period. How much lower depends on a variety of factors. The estimate used here assumed between $3 \%$ and 5\% annual growth in peak electricity demand. Thus, if the 1997 peak demand was nearly $30,000 \mathrm{MW}_{\mathrm{e}}$ (including a $10 \%$ system reserve margin), by 2017 (20 years) peak demand would be just above $54000 \mathrm{MW}_{\mathrm{e}}$ at $3 \%\left(24,000 \mathrm{MW}_{\mathrm{e}}\right.$ needed), and nearly 84,000 $\mathrm{MW}_{\mathrm{e}}$ at $5 \%$ (54,000 $\mathrm{MW}_{\mathrm{e}}$ needed). Assuming a real cost of $\$ 2500 / \mathrm{KW}_{\mathrm{e}}(\mathrm{U} . \mathrm{S} . \$ 2.5$ million/ $\mathrm{MW}_{\mathrm{e}}$ ), which is likely on the low side, between U.S.\$60 billion (R288 billion) and U.S.\$135 billion (R648 billion) capital investment is required.
} 
and constraints on public spending - does government wish to make this investment? As mentioned earlier, avoiding such large investment risk is a reason for moving from public to privately owned utilities. Brazil, for example, has been experiencing more than $6 \%$ annual economic growth. Because of the implications for public investment in electricity of such growth, Brazil decided to privatize its electricity industry, permit competition in supply to attract needed capital, and shift the investment risk from government to the private sector. While the Brazilian and South African situations are not identical, they are analogous. Consequently, it is advisable for government to seriously examine both competition and privatization of the ESI to estimate the possible benefits from this approach and compare them to the costs and impacts on other development and public policies of doing so. 


\section{Importance of Institutional Roles, Responsibility, and Alignment}

The situation in the ESI is complicated by ambiguity over institutional roles, authority, and jurisdiction. For example, the role of the Eskom Council and the Department of Public Enterprises vis $a$ vis the NER and the Department of Minerals and Energy is currently unclear. Although the NER's jurisdiction over municipal electricity distributors has been understood and largely accepted by the Department of Local Government Affairs and the municipalities themselves, its authority over Eskom remains to be clearly defined and universally accepted. The government has acknowledged this issue in the Draft Energy Policy White Paper (DME, 1998, p. 44) released in early June 1998 by stating that "...sound governance will be critical to the successful development and operation of the electricity supply industry." In this document, government proposes to clarify roles when it states, "Government will consolidate the electricity regulatory regime by establishing the powers and functions of the National Electricity Regulator through clear legislative mandate and by strengthening its capacity to achieve its mandate." This is an important policy for the government to implement. When combined with the strategic vision and principles presented in the Draft White Paper, the policy allows for a regulatory framework, administrative structure, and necessary regulatory policies to be proposed, debated, adopted, and ultimately implemented. Until this happens, however, the level of uncertainty in the ESI will remain higher than desirable. This is especially true if the structure of the distribution sector is to be altered in some fashion. It must be noted, however, that the government has been examining draft legislation to redefine and clarify the NER's role for more than 2 years. At least one of the initial drafts eliminated appeal of NER decisions to the Minister, and instead would put them in the courts. Thus, government has been reviewing the key jurisdictional issues, and therefore may be able to implement its Draft White Paper recommendation more rapidly than might be expected. As long as the authority and scope of jurisdiction over the ESI remains unclear, it will be difficult to implement a consolidation of the distribution sector whatever proposed model is chosen. This, in turn, leads to inefficiencies and unnecessary costs in the industry that must be borne by customers and can become a drag on necessary economic development.

The Draft White Paper's proposals concerning the regulatory regime represent "institution building" and means to ensure acceptance of new or refashioned institutions by the actors and stakeholders in the industry. Significant change proposed for any industry or segment of an economy must usually have stable and accepted institutions in place and functioning as a necessary condition for successful implementation of change. One reason for the present inability to adopt change for the EDI, even though all key parties agree change is needed and generally why change is necessary, is caused by the institutional ambiguity regarding NER's role and its scope of authority. The NER was created in 1995, but has yet to be fully acknowledged as the regulatory body for the electricity industry. Gaining acceptance is critical for the NER and the successful, efficient functioning of the ESI. Stable and accepted institutions are important for continuity and certainty of policy application. In the highly capital intensive electric industry, stability and continuity are crucial for attracting needed investment at a reasonable cost. Presently in South Africa, given its surplus capacity situation, new investment in generation is not an immediate issue. That will change, however, within the next 7 - 10 years. $^{28}$ Whether the regulatory regime and market structure remain publicly owned monopolies, or become more competitive with some mix of private/public ownership, the need for institutional stability and continuity remains, even if they might manifest differently in a more competitive environment.

\footnotetext{
${ }^{28}$ It is unlikely that new generating capacity will be needed within the $7-10$ year period, but given lead times for bringing capacity online investment decisions will likely have to be made during this period if not sooner.
} 
Because the government has yet to adopt a comprehensive energy policy, it is difficult for the NER to define a role that is aligned with the government's strategic objectives, the roles of other agencies, and accepted as legitimate by other major actors in the ESI. The release of the Draft Energy Policy White Paper in June 1998 is encouraging in this regard. Yet, there is no published schedule for adopting a Final Energy Policy White Paper. Furthermore, after adopted by Cabinet, specific legislation must be drafted and submitted to Parliament for its consideration and action. Given the scope, complexity, and potentially controversial nature of the policies and associated legislation, it seems unlikely that the mandate promised for the NER (which is just one part of a substantial legislative package) would be promulgated until sometime in mid- to late-1999. This may be optimistic given that national and local elections will be held in 1999. Understandably, the elections may divert parliamentary attention from anything other than the most urgent legislative matters. The argument could also be made that with an election so close at hand, no substantive actions should be taken until the electorate has the opportunity to speak about the government and its actual and proposed policies. In this sense, the election becomes a referendum on government actions and policies. If this, in fact, becomes the schedule for considering legislation needed to implement any energy policy adopted by Cabinet, it will be after the turn of the century before the ambiguity over the NER's role and responsibilities is clarified. Consequently, when combined with the other previously mentioned forces at work in the electricity supply industry, significant change is unlikely for the next 12 to 24 months. 


\section{Concluding Thoughts}

The drivers for change in the ESI are insufficient to motivate action at this time. Unless precipitated by events, significant change in the South African ESI is not likely to occur until after the 1999 national elections. The government has already ruled out increased competition or privatization for the foreseeable future and then only after rigorous study of the benefits and costs of allowing competition or privatizing some or all of the ESI or both. Furthermore, although stakeholders and government agree that the distribution segment of the ESI would benefit from consolidation, consensus on how to do so remains elusive. The approach of "muddling through" has worked so far. Therefore, without catastrophic problems the government has little incentive to begin to implement EDI change at this time.

The debate over the future of the ESI and its governance in some measure reflects two views of strategic development for South Africa: centralized/government directed versus decentralized/market driven. Both views are being considered by government, with the centralized approach seemingly ascendant at this time. There are substantial infrastructure development needs associated with the government's Reconstruction and Development Program (RDP). Given this and the government's desire to ensure that social and economic development are seen as equitable as well as efficient, it is understandable that more centralized policies for infrastructure industries like the ESI are emphasized. Yet, on the macroeconomic level, the government is supporting concepts of market economics, competition, and private sector participation. These two views are not necessarily incompatible. The argument for a mixed public/private economy can be advanced in support of combining the approaches. Government, however, has not embraced that argument. Instead, it appears that the government's position is to maintain tight policy and operational control of the ESI until its RDP goals have been substantially reached. Only then will movement to competitive markets and private ownership be seriously considered. Given the emphasis on public ownership and centralized control, defining governance forms, a regulatory regime, and assigning specific roles and responsibilities should take precedence. Considering proposals in the Draft Energy Policy White Paper, a regulatory regime based on cost-of-service pricing principles for geographically defined monopolies is most likely to emerge with the NER being the only entity with authority to economically regulate the ESI. 


\section{References}

DME (Department of Minerals \& Energy) (1998). "Draft White Paper on the Energy Policy of the Republic of South Africa."

Ministry for Provincial Affairs and Constitutional Development (1997). "Green Paper on Local Government", Pretoria, Republic of South Africa, October 1997.

Ministry in the Office of the President (1996). "Towards A National Infrastructure Investment Framework”, Reconstruction and Development Program report, March 25, 1996.

NER (National Electricity Regulator) (1997). Annual Report 1996/97. 


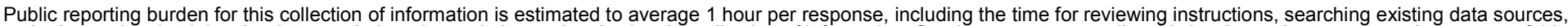

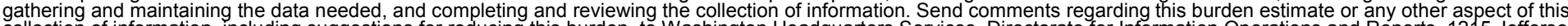

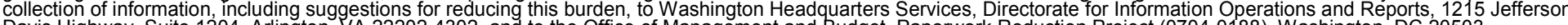

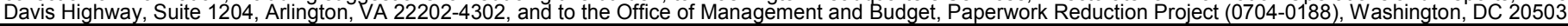

\begin{tabular}{|l|l|l|}
\hline 1. AGENCY USE ONLY (Leave blank) & $\begin{array}{l}\text { 2. REPORT DATE } \\
\text { November } 1998\end{array}$ & $\begin{array}{l}\text { 3. REPORT TYPE AND DATES COVERED } \\
\text { Technical Report }\end{array}$ \\
\hline
\end{tabular}

4. TITLE AND SUBTITLE

Grappling with Change: The South African Electricity Supply Industry
5. FUNDING NUMBERS

PV807204

PV807210

6. $\operatorname{AUTHOR}(\mathrm{S})$

Paul Galen

7. PERFORMING ORGANIZATION NAME(S) AND ADDRESS(ES)

National Renewable Energy Laboratory

1617 Cole Boulevard

Golden, Colorado 80401-3393

8. PERFORMING ORGANIZATION REPORT NUMBER

TP-260-25454

10. SPONSORING/MONITORING AGENCY REPORT NUMBER

TP-260-25454
S. Department of Energy

1000 Independence Ave., SW

Washington, DC 20585 12b. DISTRIBUTION CODE 12a. DISTRIBUTION/AVAILABILITY STATEMENT

National Technical Information Service

U.S. Department of Commerce

5285 Port Royal Road

Springfield, VA 22161

13. ABSTRACT (Maximum 200 words) This paper reviews the debate over the future structure of the South African electricity supply industry (ESI) with focus on the electricity distribution industry (EDI) segment. The importance of both new and old institutions in the ESI in facilitating change is discussed. The perspective is that of an outside observer who spent nearly 2 years following events in the South African ESI. The ESI situation reviewed here is very complex and connected to a myriad of other economic, financial, cultural, social, and political issues.

14. SUBJECT TERMS South Africa, electricity supply industry, ESI, electricity distribution industry, EDI
15. NUMBER OF PAGES

16. PRICE CODE

20. LIMITATION OF ABSTRACT

\section{OF REPORT}

unclassified
18. SECURITY CLASSIFICATION unclassified
OF ABSTRACT
unclassified
19. SECURITY CLASSIFICATION

UL

Standard Form 298 (Rev. 2-89)

Prescribed by ANSI Std. Z39-18

298-102 